\title{
Acibenzolar-S-Methyl Restricts Infection of Nicotiana benthamiana by Plantago Asiatica Mosaic Virus at Two Distinct Stages
}

\author{
Yuki Matsuo,, ${ }^{1}$ Fawzia Novianti, ${ }^{1}$ Miki Takehara, ${ }^{1}$ Toshiyuki Fukuhara, ${ }^{2}$ Tsutomu Arie, ${ }^{1}$ \\ and Ken Komatsu', ${ }^{1,+}$ \\ ${ }^{1}$ Plant Pathology Laboratory, Graduate School of Agriculture, Tokyo University of Agriculture and Technology, 3-5-8 Saiwaicho, \\ Fuchu, Tokyo 183-8509, Japan \\ ${ }^{2}$ Molecular and Cellular Biology Laboratory, Graduate School of Agriculture, Tokyo University of Agriculture and Technology \\ Accepted 11 July 2019.
}

\begin{abstract}
Plant activators, including acibenzolar-S-methyl (ASM), are chemical compounds that stimulate plant defense responses to pathogens. ASM treatment inhibits infection by a variety of plant viruses, however, the mechanisms of this broad-spectrum and strong effect remain poorly understood. We employed green fluorescent protein (GFP)-expressing viruses and Nicotiana benthamiana plants to identify the infection stages that are restricted by ASM. ASM suppressed infection by three viral species, plantago asiatica mosaic virus (PIAMV), potato virus X (PVX), and turnip mosaic virus (TuMV), in inoculated cells. Furthermore, ASM delayed the long-distance movement of PIAMV and PVX, and the cell-to-cell (short range) movement of TuMV. The ASM-mediated delay of long-distance movement of PIAMV was not due to the suppression of viral accumulation in the inoculated leaves, indicating that ASM restricts PIAMV infection in at least two independent steps. We used Arabidopsis thaliana mutants to show that the ASMmediated restriction of PIAMV infection requires the NPRI gene but was independent of the dicer-like genes essential for RNA silencing. Furthermore, experiments using protoplasts showed that ASM treatment inhibited PIAMV replication without cell death. Our approach, using GFP-expressing viruses, will be useful for the analysis of mechanisms underlying plant activator-mediated virus restriction.
\end{abstract}

Keywords: acibenzolar-S-methyl, NPR1, plant immunity, systemic acquired resistance

Plant viruses widely infect agricultural crops and damage world food production. In host plants, they have three major

${ }^{\dagger}$ Corresponding author: K. Komatsu; akomatsu@cc.tuat.ac.jp

Funding: This work was supported by a grant-in-aid for scientific research (A) from the Japan Society for the Promotion of Sciences (JSPS) (number 16H02536) to T. Arie and the Pesticide Science Society of Japan to K. Komatsu.

*The $\boldsymbol{e}$-Xtra logo stands for "electronic extra" and indicates that nine supplementary figures and two supplementary tables are published online.

The author(s) declare no conflict of interest.

@ 2019 The American Phytopathological Society infection stages, replication, cell-to-cell movement, and longdistance movement. Due to their biotrophic features, pesticides that act directly on viruses have not yet been developed. For disease control, we usually employ genetically resistant varieties or exclude insect vectors using agrochemicals. However, genetic resistance is not durable owing to viral genomic plasticity, and vector eradication has a significant environmental impact (Faoro and Gozzo 2015). Therefore, we need further studies focusing on resistance mechanisms to viral diseases, which remain poorly understood, for the development of new resistant cultivars and control methods.

Previous studies have shown that multiple phytohormones are involved in induced antiviral resistance of plants (Palukaitis et al. 2017). Among them, much research has focused on salicylic acid (SA), which plays an important role in defense signaling in general. SA induces resistance against a broad range of biotrophic pathogens through systemic acquired resistance (SAR) accompanied by pathogenesis-related (PR) gene expression and the hypersensitive response (Faoro and Gozzo 2015; Glazebrook 2005; Singh et al. 2004). Establishment of SAR through SA signaling requires NPR1, a positive regulatory hub in the SA-mediated defense responses (Yan and Dong 2014). In Arabidopsis thaliana, SA treatment inhibited infection by the oomycete pathogen Peronospora parasitica and the bacterial pathogen Pseudomonas syringae by inducing SAR (Glazebrook 2005). SA also suppresses various viral infections by interfering with different infection stages, depending on the virus-host combinations. For instance, in the tobacco mosaic virus (TMV)tobacco pathosystem, SA inhibits both replication and cell-tocell movement (Chivasa et al. 1997; Murphy and Carr 2002).

Given the importance of SA in plant resistance, agrochemicals called plant defense activators (PAs), which boost SA-related defense responses in plants, have been used for crop protection (Noutoshi et al. 2012). PAs are effective against various fungal and bacterial plant diseases and are also reported to suppress viral infection. For example, the PA probenazole promotes SA signaling upstream of SA accumulation (Bektas and Eulgem 2015) and enhances resistance to TMV in tobacco carrying the $N$ gene, which confers resistance to TMV (Nakashita et al. 2002). Another PA, acibenzolar-S-methyl (ASM) (Bektas and Eulgem 2015; Nakashita et al. 2002), acts downstream of SA accumulation and limits infection by a wide range of viruses in their susceptible host plants and enhances resistance in their resistant hosts. ASM treatment reduces the accumulation of cucurbit chlorotic yellows 
virus RNA in melon plants (Takeshita et al. 2013), suppresses the symptoms of TMV in tobacco plants without the $N$ gene, and inhibits turnip crinkle virus infection in A. thaliana (Friedrich et al. 1996; Lawton et al. 1996). ASM also induced SAR in a tobacco carrying the $N$ gene against TMV (Tripathi et al. 2010). Thus, PAs generally suppress viral infection similarly to SA. However, our understanding of the effects of PAs on viral infection remains fragmented. Because their effects vary depending on the virus species and the host plant species, we cannot draw general conclusions about how SA and PAs effectively inhibit infection by a variety of viruses (Palukaitis et al. 2017).

One possible mechanism for PA-mediated virus restriction is programmed cell death, which has been mainly studied in the context of the resistance gene-mediated hypersensitive response (Palukaitis et al. 2017). However, the available data suggest that programmed cell death may not explain all virus resistance mechanisms in plants (Greenberg and Yao 2004). Another candidate mechanism is antiviral RNA silencing, in which three Dicer-like (DCL) proteins, DCL2, DCL3, and DCL4, play critical roles (Deleris et al. 2006). Indeed, several studies have shown a link between SA signaling and antiviral RNA silencing. SA induces the activity of RNA-dependent RNA polymerase, which is necessary for the amplification of RNA silencing (Alamillo et al. 2006; Xie et al. 2001). Alamillo and associates (2006) also demonstrated that RNA silencing activity against plum pox virus decreases in transgenic tobacco plants that cannot accumulate SA. In contrast, SA treatment decreases the accumulation of TMV and cucumber mosaic virus in the Arabidopsis dcl2/dcl3/dcl4 triple mutant, which completely lacks antiviral RNA silencing activity (Lewsey and Carr 2009). Therefore, the relevance of RNA silencing in SAand PA-induced viral resistance remains unclear.

Our overall goal is to clarify how PA-induced resistance works against viral infection, in order to develop new methods for the control of plant viruses. In this study we used Nicotiana benthamiana, which is susceptible to a variety of plant viruses, with three green fluorescent protein (GFP)-expressing plant viruses, plantago asiatica mosaic virus (PlAMV), potato virus X (PVX), and turnip mosaic virus (TuMV). PIAMV and PVX are in the genus Potexvirus and TuMV is in a different genus, Potyvirus. Using these three viruses, we can compare the effect of PA on different viruses in the same genus as well as on those in different families. This system allows us to quantitatively evaluate the progression of viral infection at each of the three major infection stages. Our approach will be useful for the analysis of mechanisms underlying PA-mediated virus restriction.

\section{RESULTS}

ASM treatment restricts PIAMV-GFP infection

in the initially infected cells and delays

its long-distance movement.

PlAMV-GFP is a modified PlAMV that carries the GFP gene (Minato et al. 2014). It is based on a Li1 isolate and

A

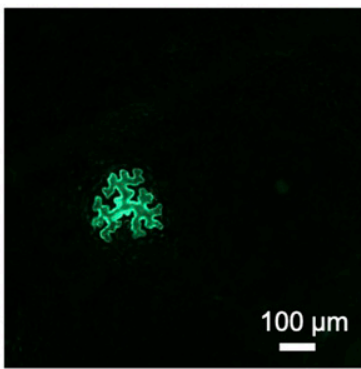

Fluorescent spot of a single cell

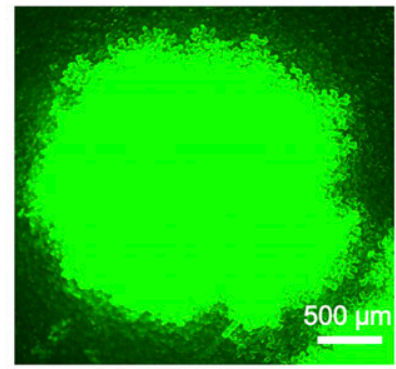

Fluorescent spot of multiple cells
B

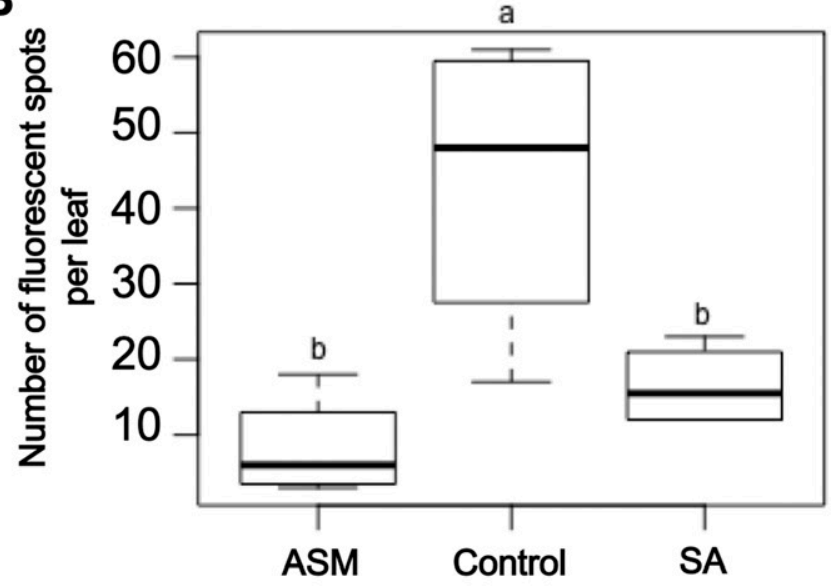

C

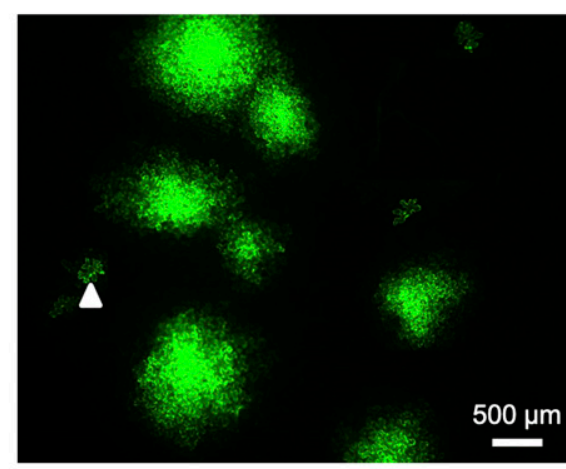

Control

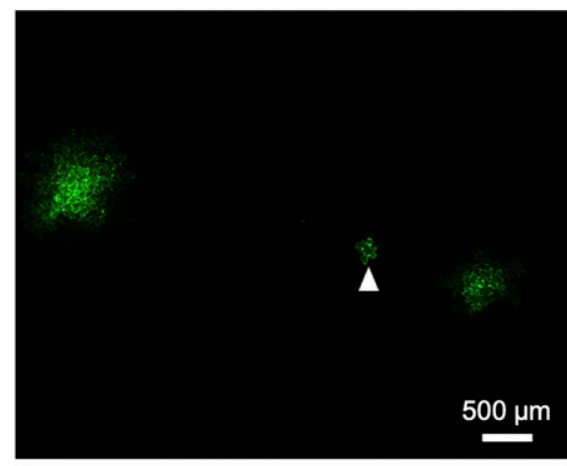

ASM

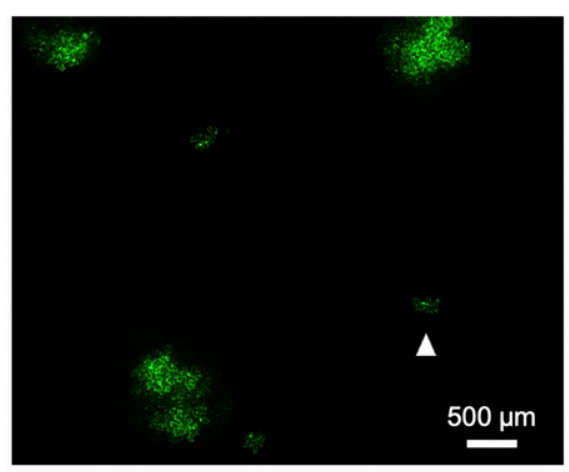

SA

Fig. 1. Effects of acibenzolar-S-methyl (ASM) and salicylic acid (SA) treatments on green fluorescent protein-expressing plantago asiatica mosaic virus (PlAMVGFP) infection of inoculated Nicotiana benthamiana leaves. A, Representative fluorescence microscopy images of inoculated leaves showing GFP fluorescence in a single cell (left; bar $=100 \mu \mathrm{m}$ ) at 2 days postinoculation (dpi) and in multiple cells (right; bar $=500 \mu \mathrm{m}$ ) at $5 \mathrm{dpi}$. B, Numbers of fluorescent spots per inoculated leaf in control plants and plants treated with $1 \mathrm{mM} \mathrm{ASM}$ or $1 \mathrm{mM} \mathrm{SA}$ at $5 \mathrm{dpi}(n=5)$. The data are representative of three independent experiments with similar results. The box plots represent the median, interquartile range, maximum, and minimum numbers. Different letters indicate significant differences among treatments $(P<0.05)$ by Duncan's multiple range test. C, Representative fluorescence microscopy images of PlAMV-GFP infection sites on inoculated leaves of control plants and $N$. benthamiana plants treated with $1 \mathrm{mM}$ ASM or $1 \mathrm{mM} \mathrm{SA}$, observed at 2 dpi. Arrowheads represent single cell spots. Bars $=500 \mu \mathrm{m}$. 
systemically infects $N$. benthamiana with mild mosaic symptoms. When we mechanically inoculate $N$. benthamiana with the PIAMV-GFP virus, fluorescence can be seen in individual cells after about 1 day (Fig. 1A, left panel). This indicates that the virus has replicated in the initially infected cells. Following this, the GFP-expressing virus spreads to adjacent cells via the plasmodesmata, resulting in the appearance of fluorescent spots containing multiple cells (Fig. 1A, right panel). Eventually the virus spreads via long-distance movement to uninoculated upper leaves and can be detected by GFP fluorescence in the uninoculated leaves (Minato et al. 2014). This pathosystem allows us to use GFP fluorescence to quantify the progress of viral infection at each step and to examine the effect of PAs on the progression of viral infection.

In order to examine the effect of ASM on viral infection, we first measured expression of the PA- and SA-inducible PR- 1 gene, to determine the appropriate timing for viral inoculation after ASM treatment. Both SA and ASM (applied by foliar spraying at $1 \mathrm{mM}$ concentration) caused relatively low levels of $P R-1$ induction at 1 and 2 days after treatment. At 3 days after treatment with either compound, the $P R-1$ transcript increased to much higher levels (Supplementary Fig. S1). This suggested that the SA-dependent defense pathway was activated by the treatments at this timepoint. It should also be noted that a $1 \mathrm{mM}$ concentration of both SA and ASM does not show any toxicity to $N$. benthamiana plants (Supplementary Fig. S2).

We treated $N$. benthamiana plants by spraying a single leaf on each plant with $1 \mathrm{mM}$ ASM or SA or water (as a control) and then inoculated the same leaf with PlAMV-GFP at 3 days after treatment. At 5 days postinoculation (dpi), we counted the number of fluorescent spots on the inoculated leaves. Both treatments reduced the number of GFP spots when compared with the controls, and there was a trend for a lower number of spots in the ASM-treated leaves compared with the SA-treated leaves, although not statistically significant (Fig. 1B). In parallel, when PlAMV-GFP was inoculated to the upper, nonsprayed leaf of the ASM-treated plants, the number of fluorescent spots was reduced compared with control plants (Supplementary Fig. S3). This result indicates that ASM can also restrict virus infection in a nontreated upper leaf, which reminds us of the SAR.

When we analyzed the effect of ASM and SA in more detail by fluorescence microscopy, we found no clear differences in the mean percentages of single cell spots versus total spots between
A
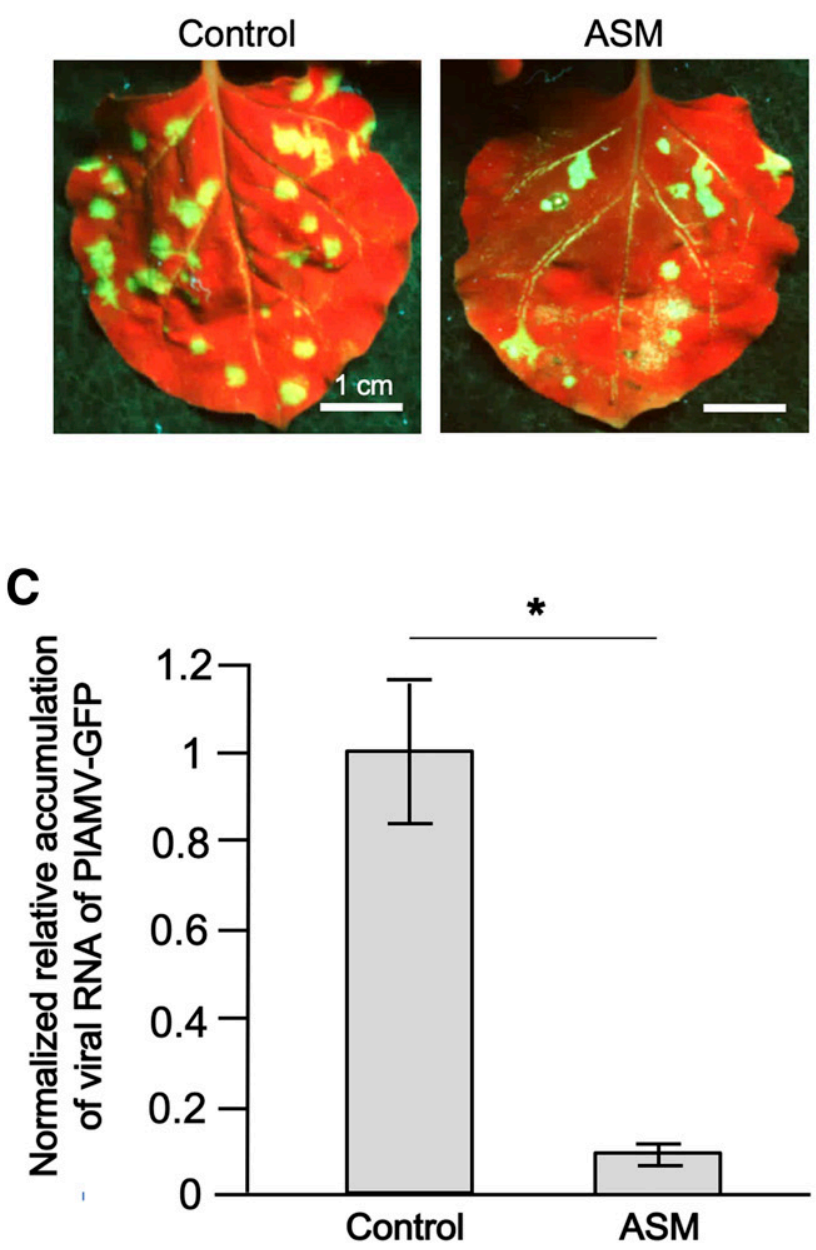

B

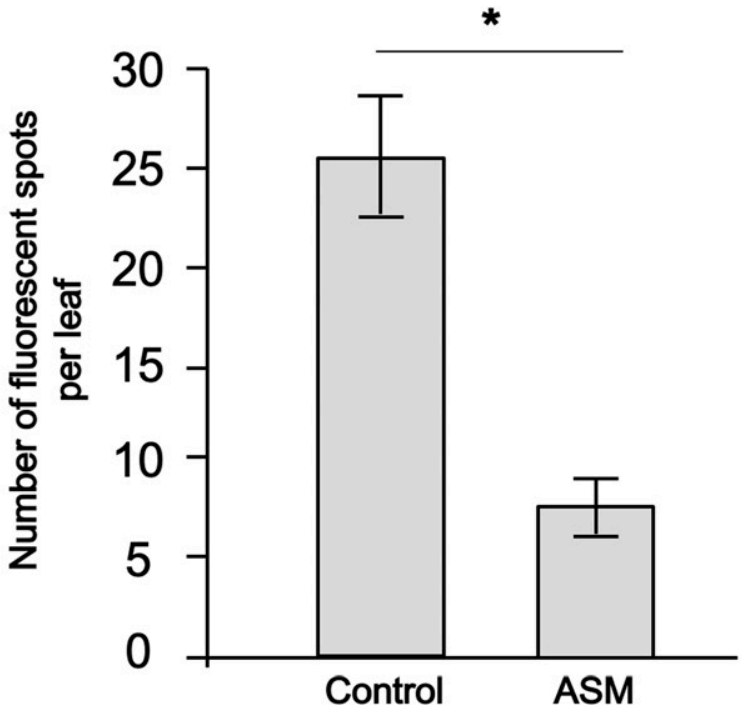

D

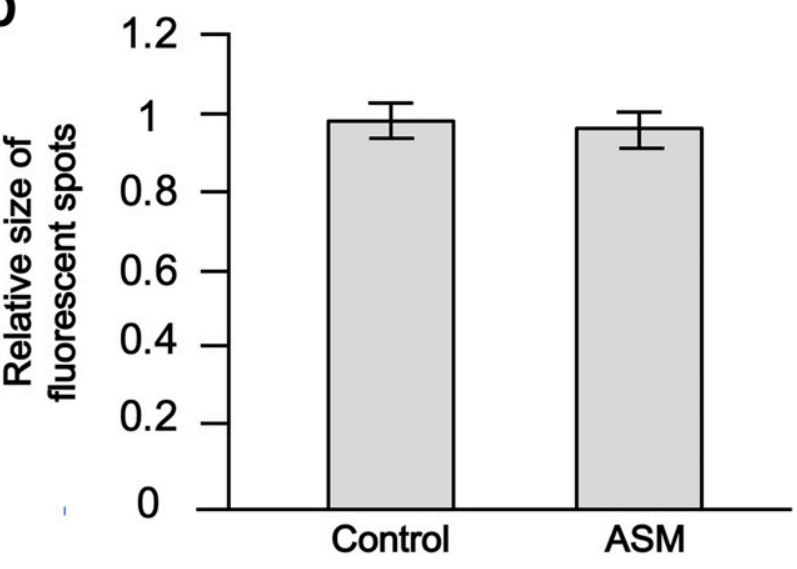

Fig. 2. Effects of acibenzolar-S-methyl (ASM) treatment on cell-to-cell movement of green fluorescent protein-expressing plantago asiatica mosaic virus (PlAMV-GFP) in inoculated Nicotiana benthamiana leaves. A, Representative photographs of control leaves and leaves treated with 1 mM ASM and inoculated with PlAMV-GFP, taken under UV light at 8 days postinoculation (dpi). Bars $=1 \mathrm{~cm}$. B, Number of fluorescent spots on inoculated leaves at 8 dpi. Data are means \pm standard error $(n=9)$. The asterisk indicates a significant difference between treatments $(P<0.05$, Student's $t$ test $)$. C, Reverse transcriptionquantitative-PCR analysis of PlAMV-GFP RNA accumulation in control leaves and leaves treated with $1 \mathrm{mM}$ ASM at 8 dpi. Data are means \pm standard error of three biological replicates, normalized to the $N$. benthamiana $18 \mathrm{~S}$ ribosomal RNA and expressed relative to the control mean. The asterisk indicates a significant difference between treatments $(P<0.05$, Student's $t$ test $)$. D, Average size of PlAMV-GFP spots at 8 dpi. Data are means \pm standard error of spot sizes calculated from those observed in a total of six leaves relative to the control mean. 
the leaves treated with ASM or SA and those treated with water at 2 dpi, although ASM significantly reduced the number of total spots by one third (Fig. 1C; Supplementary Fig. S4). In leaves treated with ASM or SA, 14.0 or $16.9 \%$ of the spots were single cells, respectively, and in the controls, $14.8 \%$ of the spots represented single cells, which was not significantly different with ASM- or SA-treated leaves (Supplementary Table S1). Similar results were obtained for three independent experiments. This result suggested that ASM treatment restricts PlAMV-GFP infection in the initially infected cells but does not restrict the cell-to-cell movement of the virus via the plasmodesmata. A similar trend was observed when we visually examined the number and size of fluorescent spots in inoculated leaves at 8 dpi. ASM treatment reduced spot number in the inoculated leaves to about one third of the number found in controls (Fig. $2 \mathrm{~A}$ and $\mathrm{B})$. In accordance with this, ASM treatment reduced viral RNA accumulation to approximately one eighth of the levels found in controls (Fig. 2C). In contrast, there were no obvious differences in the sizes of the fluorescent spots between ASM-treated and control leaves (Fig. 2D).

To determine whether ASM treatment suppresses the longdistance movement of PlAMV-GFP, we followed the time course of its long-distance movement in ASM-treated and control plants. As in the experiments we performed above, we treated a single leaf on each plant with $1 \mathrm{mM} \mathrm{ASM}$ and inoculated PIAMV-GFP in the treated leaf. This method was justified by the fact that spraying the whole plant with ASM did not increase its inhibitory effect on PlAMV infection (Supplementary Fig. S5). Based on the appearance of GFP fluorescence in uninoculated leaves, long-distance movement was detected in one control plant at $6 \mathrm{dpi}$ and had occurred in all eight control plants by $8 \mathrm{dpi}$. On the other hand, longdistance movement was not detected in any ASM-treated plants until $11 \mathrm{dpi}$ and, by $15 \mathrm{dpi}$, only five of the eight plants had shown long-distance movement of the virus (Fig. 3A and B). This result suggests that ASM treatment delays longdistance movement of PIAMV-GFP.

\section{The suppression of PIAMV-GFP infection in the inoculated leaves and the delay of its long-distance movement are independent effects of ASM treatment.}

The results shown in Figures 1 to 3 indicated that ASM treatment restricts infection of PlAMV-GFP in the initially infected cells and delays its long-distance movement. However, we could not exclude the possibility that the apparent delay in longdistance movement was due to lower amounts of the virus in the inoculated leaves. To test this possibility, we prepared a 1/4 dilution of PlAMV-GFP inoculum and performed a similar experiment to the one shown in Figure 3. The control plants treated with diluted inoculum (labeled 1/4 control plants) had similar numbers of spots and similar levels of viral RNA accumulation to those observed in ASM-treated plants inoculated with undiluted PlAMV-GFP (Fig. 4A; Supplementary Fig. S6). Based on the appearance of GFP fluorescence in the upper leaves,
A

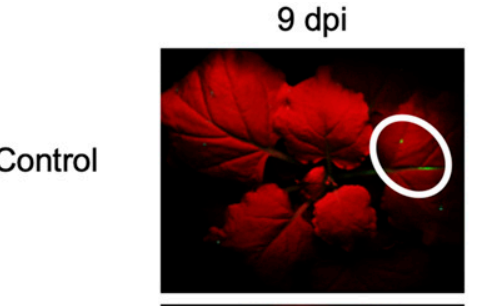

ASM

B

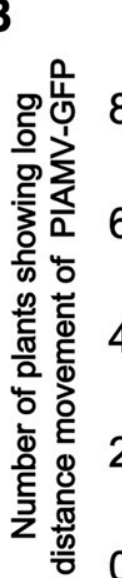

0

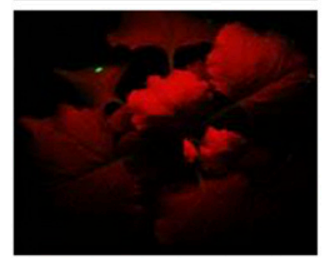

8
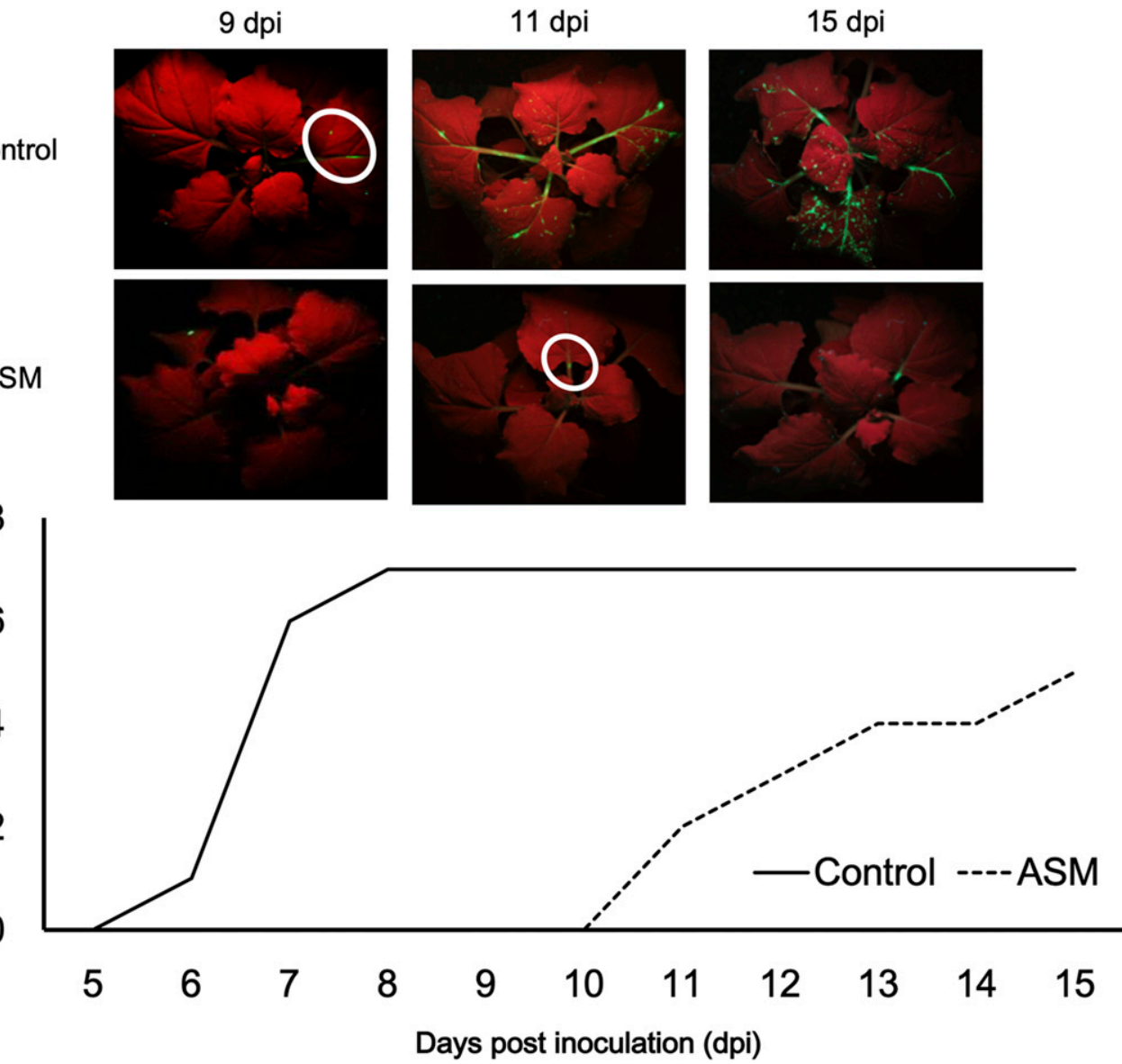

Fig. 3. Effects of acibenzolar- $S$-methyl (ASM) treatment on long-distance movement of green fluorescent protein-expressing plantago asiatica mosaic virus (PlAMV-GFP). A, Representative photographs of PlAMV-GFP fluorescence in control plants and plants treated with 1 mM ASM at 9, 11, and 15 days postinoculation (dpi), showing the long-distance spread of PlAMV-GFP to uninoculated, upper leaves of the plants. Pictures were taken under UV light. Circles indicate the first uninoculated leaves that showed GFP fluorescence. B, Kaplan-Meier curves of the time course of PlAMV-GFP movement in seven control plants (continuous line) and seven plants treated with $1 \mathrm{mM}$ ASM (dotted line). The appearance of GFP fluorescence in uninoculated leaves was recorded for each plant and the cumulative data was plotted. Statistical differences between the two curves were analyzed using the log-rank test $(P=0.00019)$. 
long-distance movement in the $1 / 4$ control plants was slightly delayed when compared with the control plants inoculated with undiluted inoculum. By $8 \mathrm{dpi}$, all the undiluted control plants and four of the five 1/4 control plants showed evidence of longdistance movement (Fig. 4C). None of the ASM-treated plants showed evidence of long-distance movement until $11 \mathrm{dpi}$, and, by $12 \mathrm{dpi}$, only three ASM-treated plants showed GFP in uninoculated upper leaves (Fig. 4B). This result suggested that the delay in long-distance movement by ASM treatment was not entirely caused by the lower amounts of virus in the inoculated leaves. Therefore, ASM treatment suppressed the primary infection stage in inoculated leaves and then delayed the longdistance movement of PlAMV-GFP in two independent steps.

\section{ASM treatment restricts PVX-GFP infection}

in the initially infected cells and delays its long-distance movement.

To determine whether ASM treatment restricts other viral infections, we next conducted similar experiments using PVX, which belongs to the same genus (Potexvirus) as PlAMV. In this case, we treated $N$. benthamiana plants by spraying single leaves with water or $0.25 \mathrm{mM}$ ASM rather than $1 \mathrm{mM}$, because PVX is more sensitive to ASM than PIAMV (data not shown). We then inoculated the same leaves with a modified PVX virus (PVX-GFP) in which GFP is expressed as a fusion protein with the coat protein, separated by the foot-and-mouth disease virus 2A peptide (Cruz et al. 1996). As for the plants inoculated with PVX-GFP, the number of GFP fluorescent spots per leaf was greatly reduced by ASM treatment, but size of the spots was not significantly affected (Fig. 5A to C). ASM treatment also caused a delay in the long-distance movement of PVX-GFP (Fig. 5D and E). Overall, these results suggest that ASM treatment inhibits infection in the initially infected cells and delays long-distance movement of PVX as it does for PlAMV.

\section{ASM treatment restricts TuMV-GFP infection} and cell-to-cell movement in the initially inoculated leaves.

Next, we investigated whether ASM treatment affects infection by TuMV, which belongs to the genus Potyvirus. We treated $N$. benthamiana plants by foliar spraying with water or

A

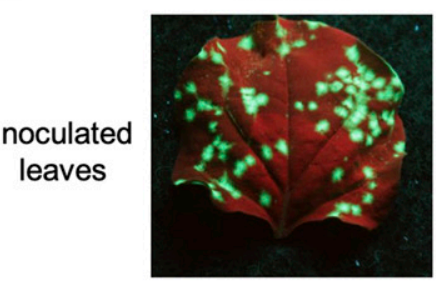

$1 / 4$ Control

ASM
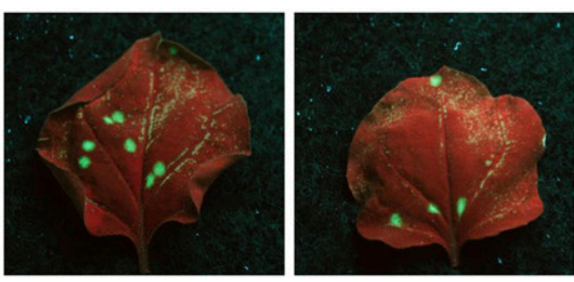

The whole plants
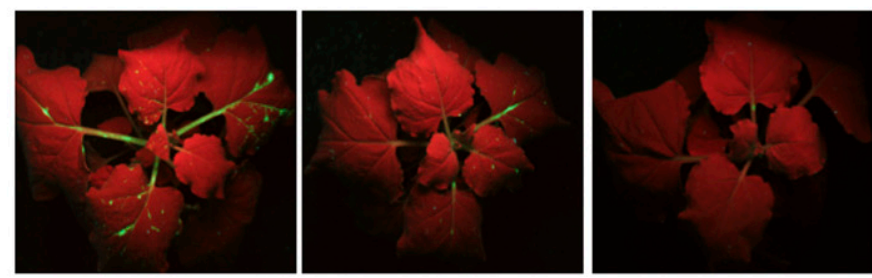

B

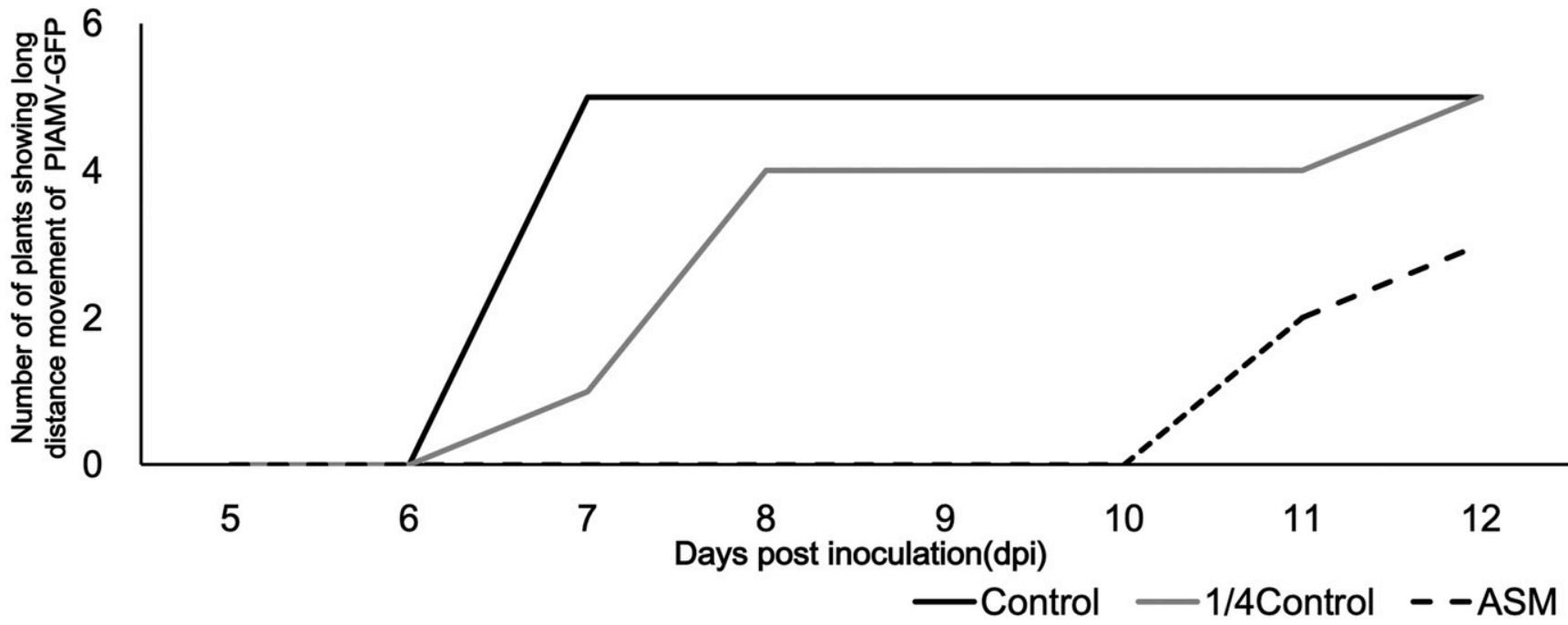

Fig. 4. Effects of inoculum dilution on long-distance movement of green fluorescent protein-expressing plantago asiatica mosaic virus (PlAMV-GFP). A, Representative photographs taken under UV light showing PlAMV-GFP infection on inoculated leaves at 8 days postinoculation (dpi) (upper panels) and on whole plants at $11 \mathrm{dpi}$ (lower panels). Left, control plants inoculated with PlAMV-GFP using the normal inoculum concentration; middle, control plants inoculated with $1 / 4$ of the normal concentration (1/4 control); right, plants treated with $1 \mathrm{mM}$ acibenzolar-S-methyl (ASM) inoculated with the normal concentration. B, Kaplan-Meier curves of the time course of PlAMV-GFP movement in control (continuous black line), 1/4 control (continuous gray line), and plants treated with $1 \mathrm{mM}$ ASM (dotted line). Five plants were used for each treatment. The appearance of green fluorescent protein fluorescence in uninoculated leaves was recorded for each plant and the cumulative data were plotted. Statistical differences between the ASM and 1/4 control curves were analyzed using the log-rank test $(P=0.039)$. 
$1 \mathrm{mM}$ ASM and then inoculated the sprayed leaves with a GFPexpressing TuMV (TuMV-GFP). In this modified virus, the GFP cistron was inserted between the RNA-dependent RNA polymerase (NIb) and coat protein cistrons (Takeshita et al. 2012). In this case, both the number and size of GFP fluorescent spots were reduced in the ASM-treated plants compared with the control plants (Fig. 6A to C). Furthermore, ASM treatment did not appear to affect the longdistance movement of TuMV-GFP, since fluorescent spots were detected in uninoculated leaves in both control and ASM-treated plants at 3 dpi and disease symptoms clearly appeared in both control and ASM-treated plants between 4 and 8 dpi (Fig. 6D). These data suggest that, unlike the potexviruses, ASM treatment restricts TuMV-GFP infection and cell-to-cell movement in the initially inoculated leaves but does not delay its long-distance movement.

\section{ASM treatment restricts PIAMV-GFP replication without cell death.}

The results described above showed that, for all three viruses tested, ASM treatment reduced the numbers of fluorescent spots in the inoculated leaves. To determine whether this reduction in the viral infection rate was manifested at the singlecell level, we prepared protoplasts from $N$. benthamiana leaves 3 days after treatment with $1 \mathrm{mM}$ ASM or water and inoculated them with PIAMV-GFP. We first measured expression of the $P R-1$ gene in the uninoculated protoplasts and found that the levels of $P R-1$ transcript were greatly increased in the ASM-treated protoplasts compared with the control protoplasts (Supplementary Fig. S7). This indicated that the SA signaling pathway was activated in the treated protoplasts. We inoculated the protoplasts with RNA transcripts of an infectious PIAMV-GFP cDNA clone and investigated the rates of infection and viral RNA accumulation at $24 \mathrm{~h}$ postinoculation (hpi). In each of five experiments, the infection rate was reduced in ASM-treated protoplasts compared with controls (Fig. 7A; Supplementary Table S2). Viral RNA accumulation in the ASM-treated protoplasts was about one fifth of the accumulation in controls (Fig. 7B). To examine whether cell death occurs at the time of virus infection, specifically after ASM treatment, we determined the percentages of viable protoplasts in uninoculated, water-inoculated, and viral RNAinoculated protoplasts, using fluorescein diacetate staining, at $24 \mathrm{hpi}$. The percentages of viable control protoplasts in all treatments were between 68 and $75 \%$, indicating that neither the mock inoculation nor the viral RNA inoculation had significant effects on protoplast viability (Fig. 7C). Viability among the ASMtreated protoplasts was around $60 \%$ for all treatments, but there were no statistically significant differences between the controls and the ASM-treated protoplasts (Fig. 7C). Therefore, neither the ASM treatment nor the viral inoculation had significant
A
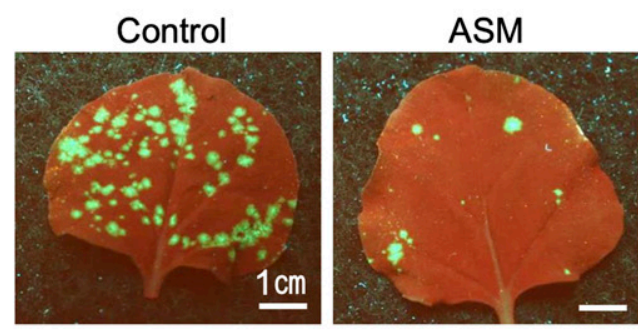

D
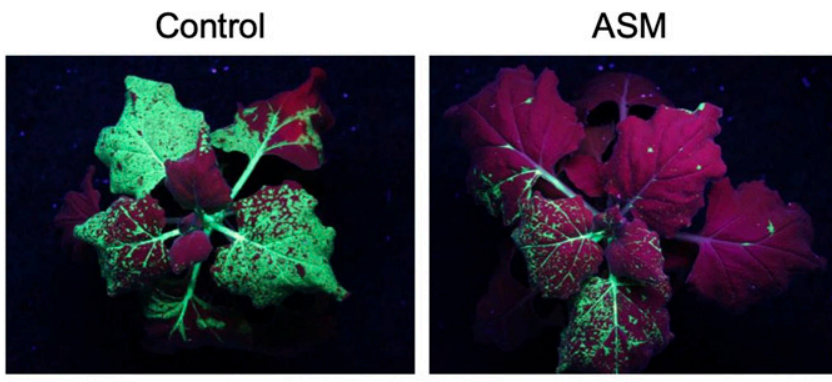

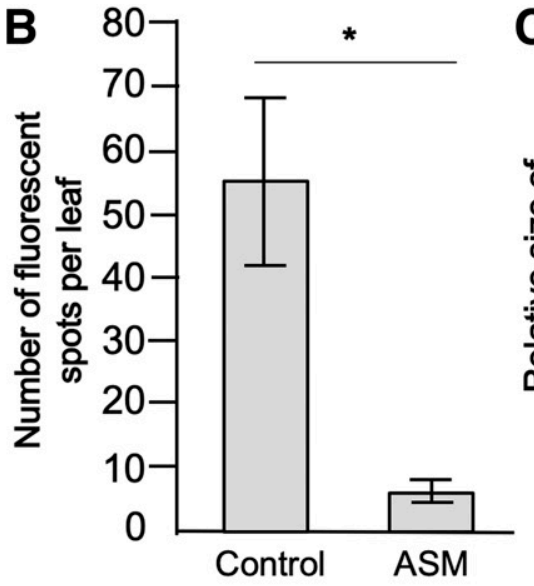

C

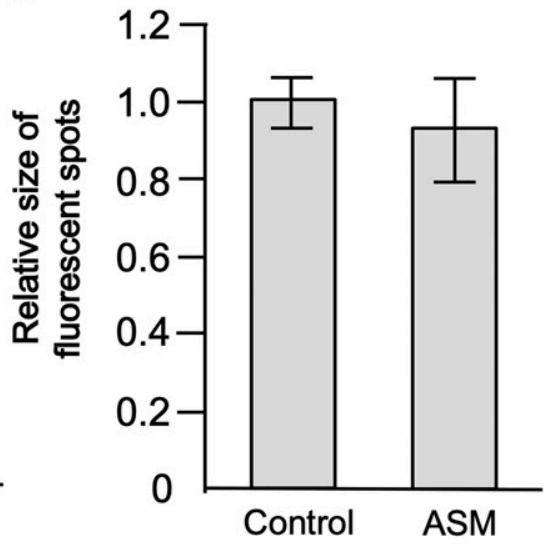

$\mathbf{E}$

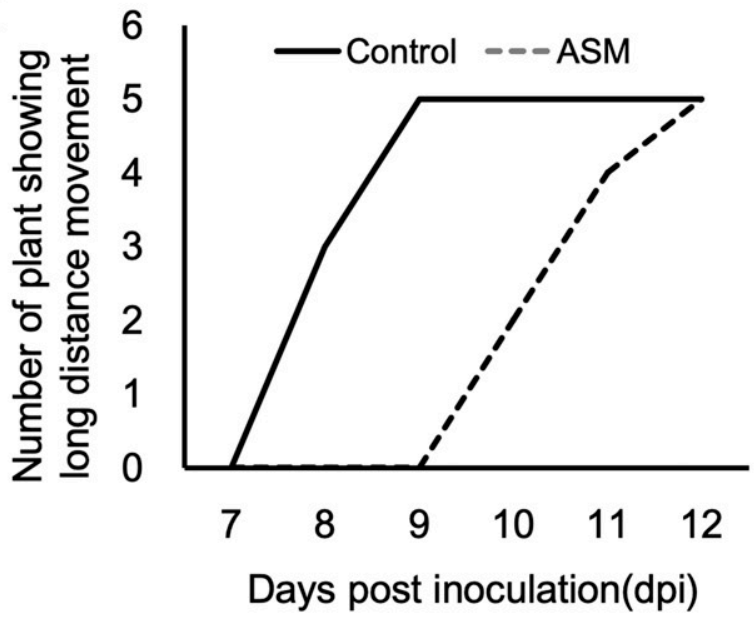

Fig. 5. Effects of acibenzolar-S-methyl (ASM) treatment on green fluorescent protein-expressing potato virus X (PVX-GFP) infection. A, Representative photographs of control leaves and leaves treated with $0.25 \mathrm{mM}$ ASM inoculated with PVX-GFP, taken under UV light at 7 days postinoculation (dpi). Bars $=1$ $\mathrm{cm}$. B, Numbers of PVX-GFP fluorescent spots on the inoculated leaves. Data are means \pm standard error $(n=9)$. The asterisk indicates a significant difference between treatments $(P<0.05$; Student's $t$ test $)$. C, Average sizes of PVX-GFP spots formed at 7 dpi. Data are means \pm standard error of spot sizes relative to the control mean $(n=7)$. D, Representative photographs of PVX-GFP fluorescence in uninoculated leaves of control plants and plants treated with $0.25 \mathrm{mM}$ ASM at 14 dpi. E, Kaplan-Meier curves of the time course of PVX-GFP movement in five control (continuous line) and five plants treated with 0.25 mM ASM (dotted line). The appearance of GFP fluorescence in uninoculated leaves was recorded for each plant and the cumulative data were plotted. Statistical differences between the two curves were analyzed using the log-rank test $(P=0.0023)$. 
effects on protoplast viability at $24 \mathrm{hpi}$. In support of these results, we did not detect any necrotic tissues in PlAMVGFP-infected $N$. benthamiana leaves stained with trypan blue, which can detect cell death in leaves infected with necrosisinducing viruses (Komatsu et al. 2010) (Supplementary Fig. S8). No cell death was observed in the infected leaves, whether or not they were pretreated with ASM. Reverse transcriptionquantitative (RT-q)PCR analysis of Nbhsr203J, a marker gene of cell death, indicated that Nbhsr203J expression was not significantly increased upon ASM treatment combined with PIAMV-GFP inoculation, which supports the above finding that cell death was not associated with the ASM-mediated virus restriction (Supplementary Fig. S9). These results indicate that ASM treatment suppresses the replication of PlAMV at the single-cell level without inducing cell death.

\section{ASM-mediated restriction of PIAMV-GFP infection in Arabidopsis thaliana requires NPR1 but} not the $D C L$ genes involved in antiviral RNA silencing.

To investigate the mechanism by which ASM treatment restricts virus infection, we took advantage of the availability of a variety of mutant lines of A. thaliana, which is susceptible to PlAMV infection (Minato et al. 2014). We first demonstrated that $1 \mathrm{mM}$ ASM treatment 3 days before inoculation reduced the number of fluorescent spots in wild type (Col-0) A. thaliana leaves at 2 dpi after inoculation with PlAMV (Fig. 8A, left panels). Therefore, ASM treatment suppresses PlAMV infection in A. thaliana, as it does in $N$. benthamiana. We then tested the effect of ASM treatment on PlAMV-GFP infection rates in several Arabidopsis defense-related mutants. However, none of the mutants other than the nprl mutant, which is deficient in NPR1, a critical signaling component of the SA-mediated defense pathway, failed to restrict PlAMV-GFP infection upon ASM treatment (data not shown). Figure 8 shows the data on the dcl2/dcl3/dcl4 (dcl2/3/4) mutant, which is deficient in antiviral RNA-silencing, and the nprl mutant. We found that ASM treatment reduced the number of fluorescent spots in PlAMV-GFP-inoculated $d c l 2 / 3 / 4$ leaves to less than half the number found in untreated leaves, as it did in the wildtype plants (Fig. 8A and B). In contrast, ASM treatment did not significantly reduce the number of fluorescent spots in the nprl mutant (Fig. 8). These results indicated that the ASM-mediated restriction of PIAMV-GFP infection requires
A
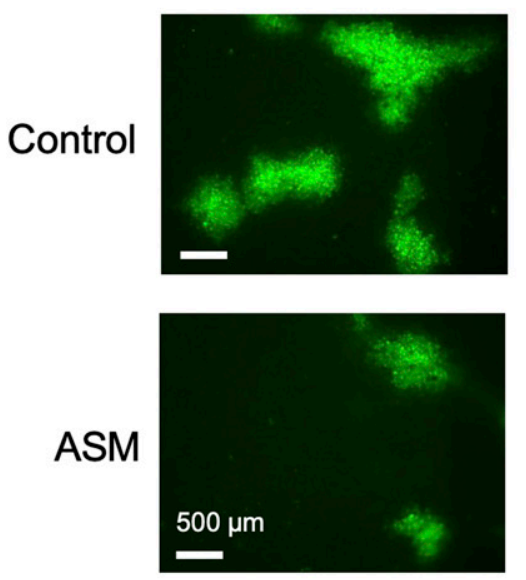

D

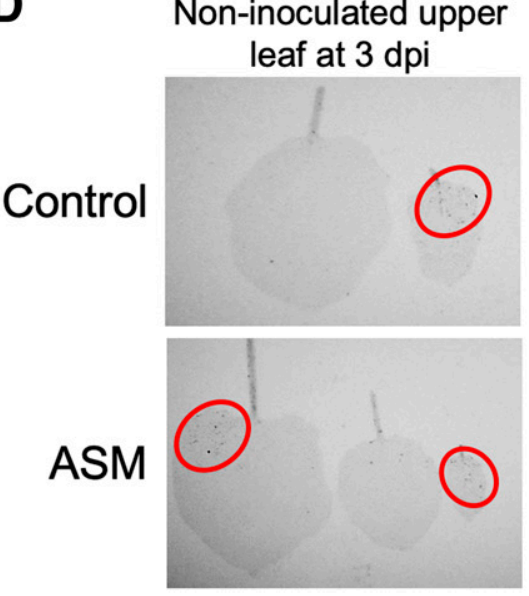

B

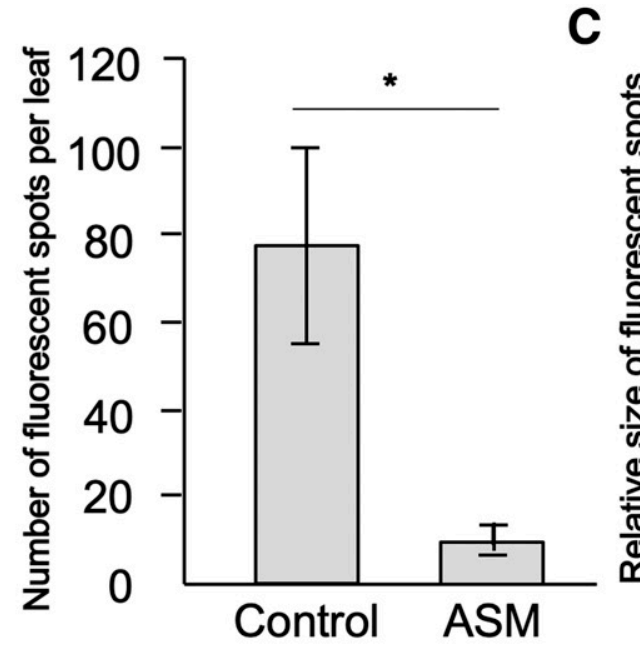

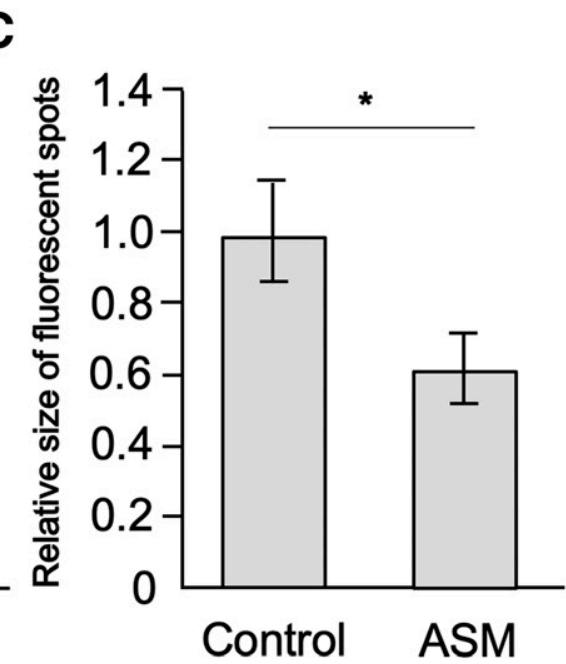

4 dpi
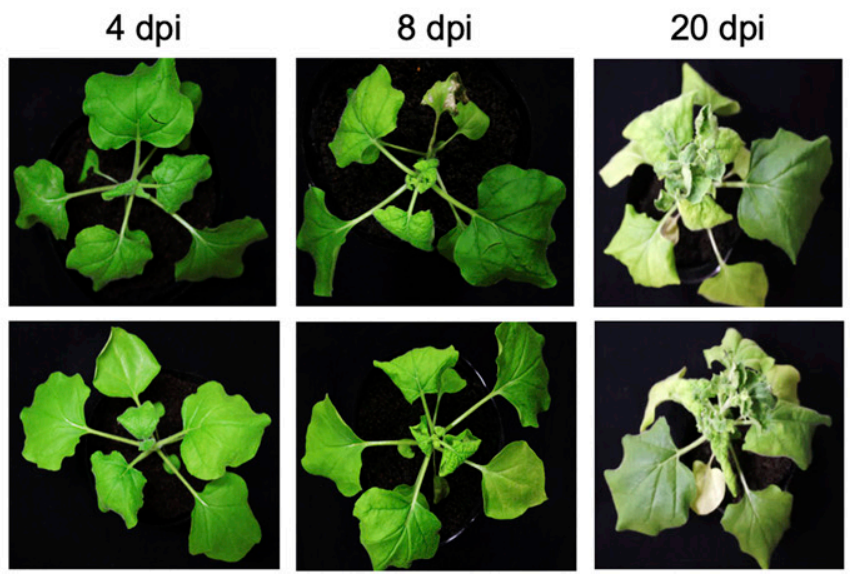

Fig. 6. Effects of acibenzolar-S-methyl (ASM) treatment on green fluorescent protein-expressing turnip mosaic virus (TuMV-GFP) infection. A, Representative fluorescence microscope images of TuMV-GFP infection sites on inoculated leaves of control Nicotiana benthamiana plants and plants treated with $1 \mathrm{mM}$ ASM observed at 2 days postinoculation (dpi). Bars $=500 \mu \mathrm{m}$. B, Number of TuMV-GFP fluorescent spots on the inoculated leaves. Data are means \pm standard error $(n=8)$. The asterisk indicates a significant difference between treatments $(P<0.05$, Student's $t$ test). C, Average size of TuMV-GFP spots formed at $2 \mathrm{dpi}$. Data are means \pm standard error of spot sizes relative to the control mean $(n=17)$. The asterisk indicates a significant difference between treatments $(P<0.05$, Student's $t$ test). D, Left, representative images of TuMV-GFP fluorescence in uninoculated upper leaves at 3 dpi, taken using a LAS-3000 luminescent image analyzer. The red circles show areas containing spots of GFP fluorescence. Right, photographs of TuMV-GFP-infected N. benthamiana plants at 4,8 , and 20 dpi. 
NPRl but does not require the DCL genes, which encode essential RNA silencing components.

\section{DISCUSSION}

PAs, including the SA analog ASM, are compounds that stimulate defense mechanisms against pathogens in plants and are widely used for crop protection. However, our knowledge of their mechanisms of action are fragmented. In this study, we developed a system for analyzing the mode of action of plant activators by tracking the progression of viral infection, viral propagation in the initially infected cells, cell-to-cell movement via the plasmodesmata, and long-distance movement. We employed GFP-expressing viruses combined with $N$. benthamiana plants to examine these stages of infection in untreated plants and in plants treated with ASM. This system enables us to examine the effects of ASM on each distinct stage of infection and thus provides insights into the mode of action of this PA in protecting plants against viral infection.

Indeed, using the system developed in this study, we found that ASM, which is one of the most studied PAs, consistently suppressed infection by three viruses (PIAMV, PVX, and TuMV) in the initially inoculated cells of $N$. benthamiana leaves. This result may seem unexpected because ASM, which activates the SA signaling pathway, was considered as an inducer of SAR. However, our results corroborate the findings of a previous study showing that the primary antiviral target of SA is replication (Singh et al. 2004). Additionally, we found that ASM inhibited the cell-to-cell movement of TuMV and delayed the long-distance movement of PIAMV and PVX. Consistent with this, previous studies on the effect of SA on TMV and cucumber mosaic virus have demonstrated that SA induces at least two distinct antiviral responses, depending on the virus (Murphy et al. 2001). However, these previous studies did not examine whether the SA-mediated inhibition of virus replication and subsequent cell-to-cell or longdistance movement were independent effects. A notable finding in our study is that the effect of ASM on long-distance movement is independent of its effect on viral propagation in the initially infected cells. We were able to demonstrate this by diluting the inoculum used to infect control plants so that the numbers of infected sites on the inoculated leaves were similar to those on ASM-treated leaves. This multistep inhibitory effect of ASM may explain its high effectiveness against various plant viruses (Palukaitis et al. 2017). Because our method for evaluating the effect of ASM can be applied to other PAs and viruses, it will be interesting to examine whether other PAs can also inhibit multiple steps of viral infection.

ASM treatment did not appear to affect the cell-to-cell movement of PlAMV-GFP or PVX-GFP, but it did appear to
A
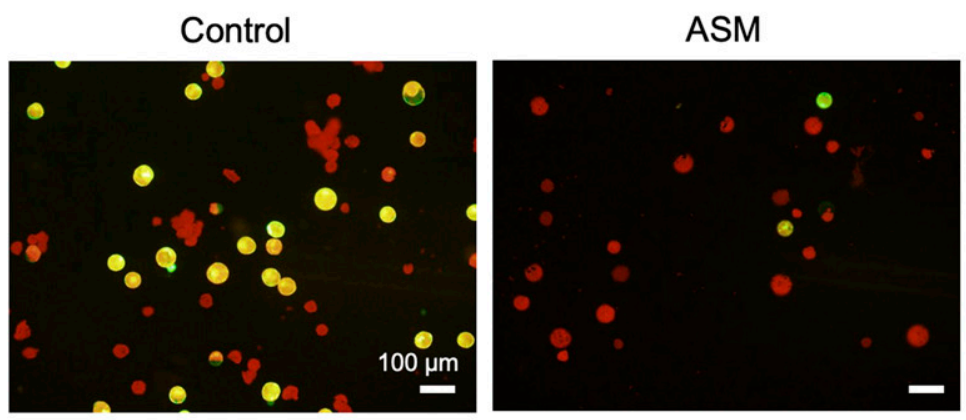

C

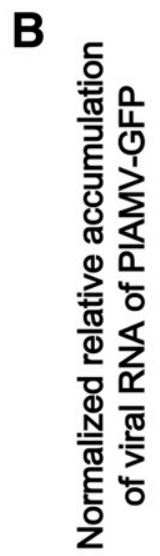

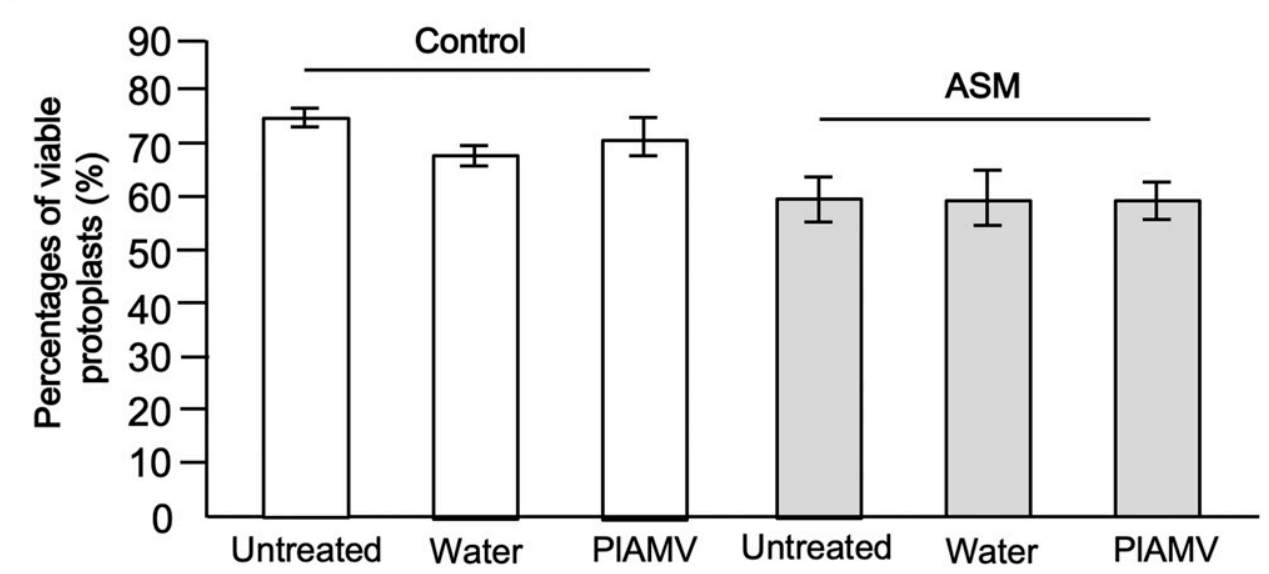

Fig. 7. Effects of acibenzolar-S-methyl (ASM) treatment on replication of green fluorescent protein-expressing plantago asiatica mosaic virus (PlAMV-GFP) in Nicotiana benthamiana protoplasts. A, Representative fluorescence microscope images of protoplasts inoculated with PlAMV-GFP RNA at 24 h postinoculation (hpi). Bars $=100 \mu \mathrm{m}$. B, Reverse transcription-quantitative PCR analysis of PlAMV-GFP RNA accumulation in protoplasts prepared from control leaves and leaves treated with $1 \mathrm{mM}$ ASM at $24 \mathrm{hpi}$. Values represent means \pm standard error of seven biologically independent replicates normalized to the $N$. benthamiana $18 \mathrm{~S}$ ribosomal RNA and expressed relative to the control mean. The asterisk indicates a significant difference between treatments $(P<0.05$, Student's $t$ test). C, Percentages of viable protoplasts prepared from control $N$. benthamiana leaves and leaves treated with 1 mM ASM. Each protoplast preparation was either uninoculated, mock-inoculated with water, or inoculated with the PlAMV-GFP RNA. Viable protoplasts were visualized and counted using fluorescein diacetate staining at 24 hpi. Bars represent means \pm standard error $(n=6)$. 
inhibit the cell-to-cell movement of TuMV-GFP. However, caution is needed in the interpretation of these results, since the ASM treatment also inhibited viral replication in the initially infected cells. In this and other studies, leaves were treated uniformly with ASM, and thus, we would expect that viral replication would be inhibited in neighboring cells as well as the initially infected cells. Therefore, our results for TuMVGFP might be due to the ASM-mediated inhibition of replication in the neighboring cells rather than a specific effect of ASM on cell-to-cell movement. Regardless of this possibility, ASM treatment did not reduce fluorescent spot size in leaves inoculated with PlAMV-GFP and PVX-GFP, even though it restricted viral propagation in the initially infected cells. It is possible that different strategies of cell-to-cell movement employed by potexviruses and potyviruses can affect the outcome of ASM-mediated inhibition in their initially infected cells and their neighboring cells. Future studies should include an experiment that would reveal whether the restrictive effect of ASM on the replication (represented by the number of spots) and the cell-to-cell movement (represented by the size of spots) are dependent or not.

We also took advantage of an Arabidopsis-PlAMV pathosystem that has been used to identify host factors that affect the infection of plants by viruses (Yamaji et al. 2012; Hashimoto et al. 2016). NPR1 is the positive and central regulator of PR gene expression and SAR downstream of SA and ASM. We demonstrated that NPR1 was needed for the ASM-mediated inhibition of PlAMV infection in inoculated leaves. This finding differs from previous studies showing that PA-induced antiviral responses are independent of NPR1 (Carr et al. 2010). In studies with $A$. thaliana, NPR1 was reported to be dispensable for both the SA-induced inhibition of turnip vein clearing virus and resistance to turnip crinkle virus, which is mediated by the dominant resistance gene HRT (Kachroo et al. 2000; Wong et al. 2002). On the other hand, in $N$. benthamiana plants transformed with the $N$ gene, the $N$-mediated resistance to TMV requires NPR1, even though the $N$ gene encodes a nucleotide binding site leucine-rich repeat protein similar to HRT (Liu et al. 2002). These findings, combined with the results of this study, highlight differences in the requirement of NPR1 for antiviral responses among plant-virus pathosystems.

An unanswered question that needs to be addressed is what kinds of genes and pathways downstream of NPR 1 are involved in the restriction of virus infection. Although proteins encoded by PR genes, whose expression is induced downstream of NPR1, are candidates, molecular evidence for their antiviral roles is scarce (Ali et al. 2018). One of the more possible mechanisms is RNA silencing, which is an essential antiviral defense response. However, ASM treatment reduced the number of PIAMV-GFP fluorescent spots in the inoculated leaves of the RNA silencing-deficient $d c l 2 / d c l 3 / d c l 4$ triple mutant, indicating that RNA silencing is not involved in the ASMmediated suppression of PlAMV-GFP infection (Fig. 8). This result is consistent with a previous study showing that DCL2,
A

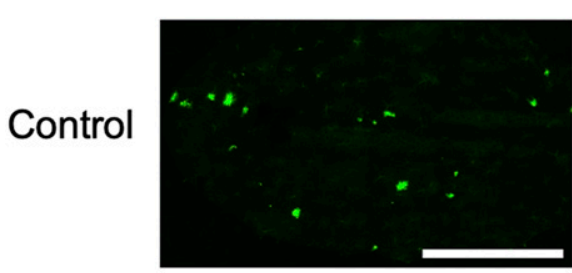

ASM

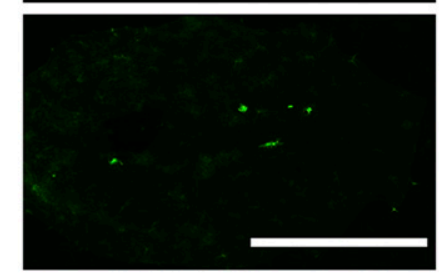

Col-0
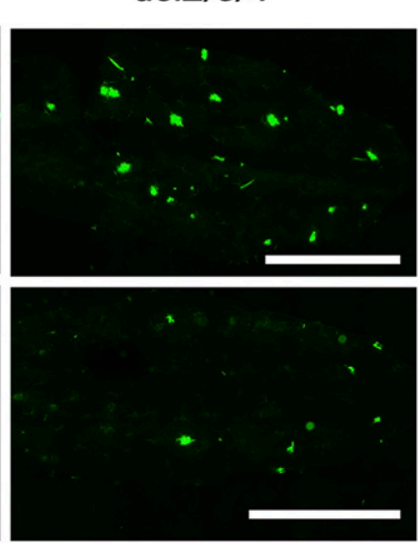

B

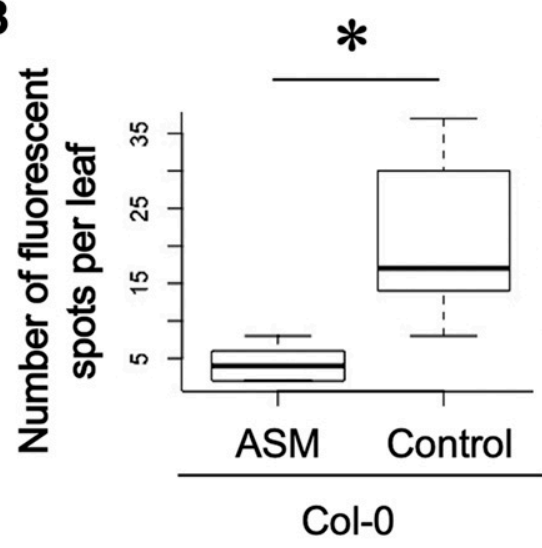

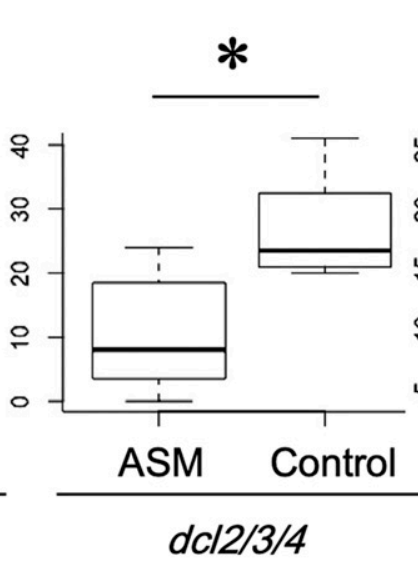
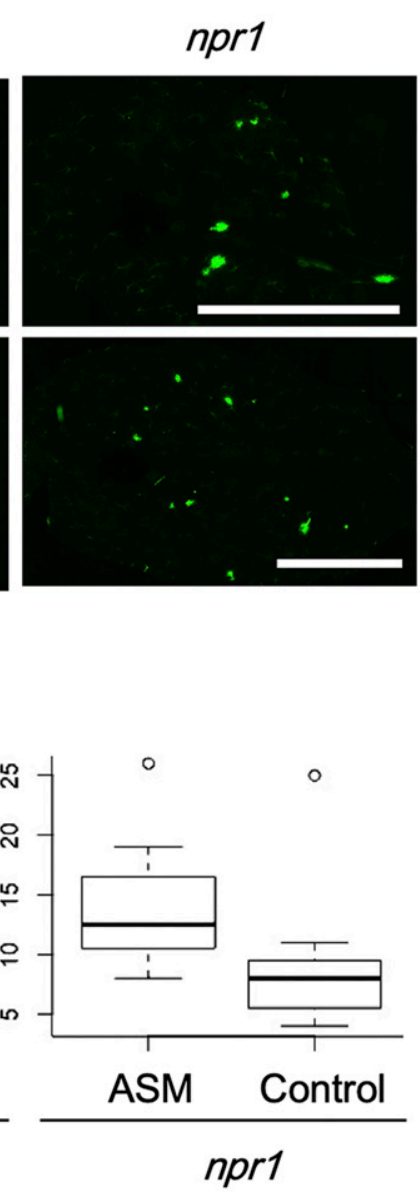

Fig. 8. Effects of acibenzolar-S-methyl (ASM) treatment on green fluorescent protein-expressing plantago asiatica mosaic virus (PIAMV-GFP) infection in wild type and mutant lines of Arabidopsis thaliana. A, Representative photographs taken under UV light showing spots of PlAMV-GFP infection in inoculated leaves of plants treated with $1 \mathrm{mM}$ ASM and control plants at 2 days postinoculation (dpi). Bars $=5 \mathrm{~mm}$. Left, Col-0 (the wild type); middle, the $d c l 2 / 3 / 4$ mutant; right, the nprl mutant. B, Numbers of fluorescent spots on whole inoculated leaves at 2 dpi $(n=8)$. The results are representative of three independent experiments with similar results. The box plots represent the median, interquartile range, maximum, and minimum numbers. Small circles in the plot of $n p r l$ mutant represent outliers. The asterisks indicate significant differences from the control leaves inoculated with the normal concentration $(P<0.05$, Student's $t$ test). 
DCL3, and DCL4 are dispensable for the SA-induced inhibition of TMV and cucumber mosaic virus infection (Lewsey and Carr 2009).

Another candidate mechanism for the ASM-mediated suppression of virus infection is programmed cell death. However, we showed that, in $N$. benthamiana protoplasts, ASM treatment decreased viral accumulation but did not increase the rate of cell death, indicating that the ASM-mediated inhibition of viral replication cannot be explained by cell death (Fig. 7). In accordance with this result, several previous reports have shown that some resistance genes against plant viruses inhibit their replication without cell death. For example, cell death did not occur in protoplasts prepared from N. tabacum cv. Samsun NN, which exhibits the $N$-dependent hypersensitive response upon TMV infection (Otsuki et al. 1972). Further, $R x$-mediated resistance completely suppressed PVX infection without cell death in potato protoplasts (Bendahmane et al. 1999). Recently, the jacalin-type lectin JAX1 was shown to inhibit the replication of potexviruses by targeting the viral replication complex (Yoshida et al. 2019). It is possible that ASM treatment induces expression of an unidentified antiviral resistance gene that does not activate programmed cell death, leading to the rapid inhibition of viral replication.

An alternative but not mutually exclusive mechanism involves inhibition of viral replication as a side effect of the antifungal and antibacterial functions of the SA signaling pathway. For example, the protein secretory pathway, which is required for resistance against bacterial pathogens, is induced downstream of NPR1 (Wang et al. 2005). Massive induction of the NPR1-dependent secretory pathway upon ASM treatment may perturb the regular organization of intracellular membranes, in which plant viruses establish their replication complexes (Grangeon et al. 2012).

In this study, we have developed a system that can be used to track the progression of viral infection through three distinct steps. This system can be used with a variety of viruses and plant hosts under a variety of treatment conditions, to identify the steps affected by particular treatments in each pathosystem. Furthermore, the use of mutants such as the Arabidopsis dcl2/dcl3/dcl4 and nprl mutants allows us to identify host factors that affect the progression of viral infection through each stage. This study will stimulate future research to resolve the unknown mechanisms of PA-mediated restriction of plant virus infection. This approach could also be used to identify more effective PAs, possibly leading to more efficient approaches to the control of viral diseases.

\section{MATERIALS AND METHODS}

\section{Plant materials and PA and SA treatment.}

$N$. benthamiana plants were grown in a growth chamber under a 16 -h light and 8-h dark cycle at $25^{\circ} \mathrm{C}$. Arabidopsis thaliana was grown in a growth chamber under a 12-h light and 12-h dark cycle at $22^{\circ} \mathrm{C}$. Seeds of the nprl-1 (CS3726) and $d c l 2 / d c l 3 / d c l 4$ (CS16391) A. thaliana mutants were provided by the Arabidopsis Biological Resource Center (Columbus, OH, U.S.A.). Four- to 5-week-old N. benthamiana plants and 3-week old A. thaliana plants were treated with ASM or water by foliar spraying and were incubated under the same conditions. ASM (50\% [wt/wt] active ingredient; Syngenta, Tokyo) and sodium salicylate (Sigma-Aldrich, St. Louis) were dissolved in water containing $0.004 \%$ (vol $/ \mathrm{vol})$ Silwet L-77 (Nippon Unicar, Kawasaki, Japan) to a final concentration of $1 \mathrm{mM}$, unless otherwise stated. Water containing Silwet L-77 was used as a control. The ASM, SA, and water were applied to one leaf of each $N$. benthamiana plant.

\section{Viruses, purification, and inoculation.}

PlAMV-GFP (Minato et al. 2014) and PVX-GFP (Cruz et al. 1996) express their GFP as a fusion protein with the coat protein, separated by the foot-and-mouth disease virus $2 \mathrm{~A}$ peptide. TuMV-GFP (Takeshita et al. 2012) expresses its GFP as a part of a polyprotein, in which the GFP cistron is inserted into the junction between the NIb and coat protein cistrons.

In order to produce purified virions for the mechanical inoculation of ASM- or SA-treated leaves, we first propagated the viruses in $N$. benthamiana. For PlAMV-GFP and PVX-GFP, virus infection was launched by infiltration with an agrobacterium culture (optical density at $600 \mathrm{~nm}=1.0$ ) carrying a binary vector containing viral DNA (Minato et al. 2014). For TuMV-GFP, infection was initiated by mechanical inoculation with a plasmid containing the viral cDNA (Takeshita et al. 2012). Systemically infected leaves were collected 5 to $7 \mathrm{dpi}$ and were stored at $-80^{\circ} \mathrm{C}$, until use. Virus particles of PlAMVGFP and TuMV-GFP were prepared, from these infected leaves, using a polyethylene glycol (PEG) precipitation procedure, essentially as described previously (AbouHaidar et al. 1998; Garcia-Ruiz et al. 2010). For the preparation of PlAMV-GFP virions, a subsequent centrifugation step with a $20 \%$ sucrose cushion was also performed. For PVX-GFP, three leaf disks $5 \mathrm{~mm}$ in diameter were excised at 3 to $5 \mathrm{dpi}$ using a cork borer, were ground with $1 \mathrm{ml}$ of $0.2 \mathrm{M}$ sodium phosphate buffer, and were directly used for inoculation. Each virus-enriched pellet of PlAMV-GFP and TuMV-GFP was resuspended in RNase-free water (Funakoshi, Tokyo) containing recombinant RNase inhibitor (TaKaRa Bio, Otsu, Japan).

Three days after spraying with ASM or water, treated leaves (one per plant) were mechanically inoculated with virus particles (PIAMV, 350 ng per leaf; TuMV, 660 ng per leaf) or a virus solution, in the case of PVX (10 $\mu$ l per leaf), using Carborundum as an abrasive.

\section{Fluorescence microscopy, image analysis, and trypan blue staining.}

Viral-expressed green fluorescence images were acquired at 2 or 3 dpi, using a BIOREVO BZ-9000 microscope (Keyence, Osaka, Japan) with GFP filter sets, and the data was processed using the inbuilt data analysis software. Fluorescence images of inoculated leaves or whole plants infected with PlAMV-GFP or PVX-GFP were acquired using a handheld UVGL-58 UV lamp (Funakoshi) and a DS126231 camera (Canon, Tokyo), with an exposure time of $15 \mathrm{~s}$. The numbers of fluorescent spots in each image was counted manually, and the size of fluorescent spots was measured using ImageJ software (National Institutes of Health, Bethesda, MD, U.S.A.). Fluorescence images of inoculated leaves or upper leaves infected with TuMV-GFP were acquired using a LAS-3000 imager (Fujifilm, Tokyo), with an exposure time of $15 \mathrm{~s}$. Trypan blue staining was performed by boiling the inoculated leaves for $3 \mathrm{~min}$ in ethanol-lactophenol (2:1) containing $0.02 \%$ (wt/vol) trypan blue. The stained leaves were decolorized in a chloral hydrate solution $(1 \mathrm{~kg}$ of chloral hydrate in $400 \mathrm{ml}$ water) for at least 1 day.

\section{RNA extraction and RT-qPCR.}

A total of about $0.1 \mathrm{~g}$ of leaf tissues from two different leaves were homogenized in liquid nitrogen and total RNA was isolated, using ISOGEN reagent (Wako, Osaka, Japan) according to manufacturer instructions. Each RNA sample was treated with RQ1 RNase-free DNase (Promega, Madison, WI, U.S.A.), and about $1 \mu \mathrm{g}$ of the DNase-treated total RNA was reverse transcribed, using the high-capacity cDNA reverse transcription kit (Thermo Fisher Scientific, Waltham, MA, U.S.A.), following manufacturer protocols. For monitoring PlAMV RNA accumulation and $P R-1$ expression, $2 \mu l$ of synthesized cDNA was used 
for RT-qPCR, using the Thermal cycler dice real time system II MRX [TP960] (TaKaRa Bio) with GoTaq qPCR master mix (Promega). 18S rRNA was used as an internal control.

The primer sets used for RT-qPCR were: PlAMV-3877F (5' CCTCATTCTCCCTGCTGAAG-3') and PIAMV-4010R (5'-CT TGAGGGGGTCTTTGATGA-3') for PlAMV genomic RNA (Tanaka et al. 2019); NtPR1a-238F (5'-CATGGTCAATACGG CGAAAACCTAG-3') and NtPR1a-322R (5'-TCTCATCGACC CACATCTCAACG-3') for $P R-1$; Nb18S-193F (5'-ATACGTGC AACAAACCCCGAC-3') and Nb18S-280R (5'-TGAATCAT CGCAGCAACGG-3') for the $18 S$ rRNA (Hashimoto et al. 2012); and Nbhsr203J-F-SC57 (5'-CGCAATTCCAATCCAT CCAGGCTT-3') and Nbhsr203J-R-SC58 (5'-GCAATTTAAGC TCCTCAACCGCCT-3') for Nbhsr203J (Wei et al. 2013).

\section{Protoplast preparation and infection.}

For inoculation of protoplasts with PlAMV-GFP, we first constructed T7-Li1-GFP, from which the infectious Li1-GFP genomic RNA can be transcribed in vitro, based on the binary vector pLi1-GFP (Minato et al. 2014), for agroinoculation with the PIAMV Li1 isolate carrying the sGFP gene. PCR was carried out using pLi1-GFP as a template, with the primer T7-Li1-1F (5'-GTAATACGACTCACTATAGAAAACAAACC TACACAAACCA-3') that has the T7 promoter sequence at its $5^{\prime}$ terminus and a poly(T) primer with the downstream ClaI restriction enzyme site (5'-ATCGATTTTTTTTTTTTTTTTT TTTTTTTTTTTTTTV-3'), and the amplification product was cloned into the plasmid pBluescript SK+. The T7-Li1-GFP virus construct was digested at the ClaI site just downstream of the poly(A) sequence. The viral PlAMV-GFP RNAs were transcribed from the linearized plasmids with the MEGAscript T7 transcription kit (Thermo Fisher Scientific), according to manufacturer instructions. The $\mathrm{m}^{7} \mathrm{GpppG}$ cap analog (New England Biolabs, Ipswich, MA, U.S.A.) was included in the reaction. After the transcription, the quality and integrity of the RNA were confirmed using polyacrylamide gel electrophoresis.

Leaves of about 40-day-old $N$. benthamiana plants were used for protoplast preparation. The abaxial epidermis of each expanded leaf was peeled off and was floated in enzyme solution consisting of $0.5 \mathrm{M}$ mannitol, $1.8 \mathrm{mM}$ MES, $20 \mathrm{mM}$ $\mathrm{KCl}, 10 \mathrm{mM} \mathrm{CaCl} 2,0.05 \%$ macerozyme R-10 (Kinki Yakult Co., Nishinomiya, Japan), and $1 \%$ cellulase "Onozuka" R-10 (Kinki Yakult Co.) for $3 \mathrm{~h}$ at $26^{\circ} \mathrm{C}$. The density of the isolated protoplasts was adjusted to $5 \times 10^{5}$ to $10 \times 10^{5}$ protoplasts per milliliter. The protoplast solution $(1 \mathrm{ml})$ was inoculated with $1 \mu \mathrm{g}$ of capped in vitro transcribed virus RNA in PEG-calcium transfection solution (40\% [wt/vol] PEG 1540 [Polysciences, Inc., Warrington, PA, U.S.A.] and $3 \mathrm{mM} \mathrm{CaCl} 2$ ). After inoculation the protoplasts were suspended in incubation buffer (0.5 M mannitol, $1 \times$ Aoki salts $\left(0.2 \mathrm{mM} \mathrm{KH}_{2} \mathrm{PO}_{4}, 1 \mathrm{mM}\right.$ $\mathrm{KNO}_{3}, 1 \mathrm{mM} \mathrm{MgSO}, 10 \mathrm{mM} \mathrm{CaCl}, 1 \mu \mathrm{M} \mathrm{KI}, 0.1 \mu \mathrm{M}$ $\mathrm{CuSO}_{4}, \mathrm{pH}$ 6.5) (Kroner and Ahlquist 1992) and were incubated for $24 \mathrm{~h}$ at $25^{\circ} \mathrm{C}$ in the dark. For analyses of the percentages of protoplast viability and infection rates of PlAMV-GFP, approximately 1,000 protoplasts were observed, using fluorescence microscopy. Extraction of total RNA from protoplasts was performed as described previously (Kroner and Ahlquist 1992). Total RNA (200 ng) extracted from the protoplasts was used for RT-qPCR.

\section{ACKNOWLEDGMENTS}

We are grateful to Y. Nakajima at Syngenta Japan for providing ASM, T. Natsuaki at Utsunomiya University for providing TuMV-GFP, and D. C. Baulcombe at the University of Cambridge for PVX-GFP. We also thank to the Arabidopsis Biological Resource Center for providing the $d c l$ - and nprl-deficient lines of A. thaliana.

\section{LITERATURE CITED}

AbouHaidar, M. G., Xu, H., and Hefferon, K. L. 1998. Potexvirus isolation and RNA extraction. Pages 131-143 in: Plant Virology Protocols. Methods in Molecular Biology, vol. 81. G. D. Forster and S. C. Taylor, eds. Humana Press, Totowa, NJ, U.S.A.

Alamillo, J. M., Saénz, P., and García, J. A. 2006. Salicylic acid-mediated and RNA-silencing defense mechanisms cooperate in the restriction of systemic spread of plum pox virus in tobacco. Plant J. 48:217-227.

Ali, S., Ganai, B. A., Kamili, A. N., Bhat, A. A., Mir, Z. A., Bhat, J. A., Tyagi, A., Islam, S. T., Mushtaq, M., Yadav, P., Rawat, S., and Grover, A. 2018. Pathogenesis-related proteins and peptides as promising tools for engineering plants with multiple stress tolerance. Microbiol. Res. 212213:29-37.

Bektas, Y., and Eulgem, T. 2015. Synthetic plant defense elicitors. Front. Plant Sci. 5:804.

Bendahmane, A., Kanyuka, K., and Baulcombe, D. C. 1999. The $R x$ gene from potato controls separate virus resistance and cell death responses. Plant Cell 11:781-791.

Carr, J. P., Lewsey, M. G., and Palukaitis, P. 2010. Signaling in induced resistance. Adv. Virus Res. 76:57-121

Chivasa, S., Murphy, A. M., Naylor, M., and Carr, J. P. 1997. Salicylic acid interferes with tobacco mosaic virus replication via a novel salicylhydroxamic acid-sensitive mechanism. Plant Cell 9:547-557.

Cruz, S. S., Chapman, S., Roberts, A. G., Roberts, I. M., Prior, D. A., and Oparka, K. J. 1996. Assembly and movement of a plant virus carrying a green fluorescent protein overcoat. Proc. Natl. Acad. Sci. U.S.A. 93: 6286-6290

Deleris, A., Gallego-Bartolome, J., Bao, J., Kasschau, K. D., Carrington, J. C., and Voinnet, O. 2006. Hierarchical action and inhibition of plant Dicer-like proteins in antiviral defense. Science 313:68-71.

Faoro, F., and Gozzo, F. 2015. Is modulating virus virulence by induced systemic resistance realistic? Plant Sci. 234:1-13.

Friedrich, L., Lawton, K., Ruess, W., Masner, P., Specker, N., Rella, M. G., Meier, B., Dincher, S., Staub, T., Uknes, S., Métraux, J. P., and Ryals, J. 1996. A benzothiadiazole derivative induces systemic acquired resistance in tobacco. Plant J. 10:61-70.

Garcia-Ruiz, H., Takeda, A., Chapman, E. J., Sullivan, C. M., Fahlgren, N., Brempelis, K. J., and Carrington, J. C. 2010. Arabidopsis RNAdependent RNA polymerases and dicer-like proteins in antiviral defense and small interfering RNA biogenesis during Turnip Mosaic Virus infection. Plant Cell 22:481-496.

Glazebrook, J. 2005. Contrasting mechanisms of defense against biotrophic and necrotrophic pathogens. Annu. Rev. Phytopathol. 43:205-227.

Grangeon, R., Jiang, J., and Laliberté, J. F. 2012. Host endomembrane recruitment for plant RNA virus replication. Curr. Opin. Virol. 2:683-690.

Greenberg, J. T., and Yao, N. 2004. The role and regulation of programmed cell death in plant-pathogen interactions. Cell. Microbiol. 6:201-211.

Hashimoto, M., Komatsu, K., Maejima, K., Okano, Y., Shiraishi, T., Ishikawa, K., Takinami, Y., Yamaji, Y., and Namba, S. 2012. Identification of three MAPKKKs forming a linear signaling pathway leading to programmed cell death in Nicotiana benthamiana. BMC Plant Biol. 12:103

Hashimoto, M., Neriya, Y., Yamaji, Y., and Namba, S. 2016. Recessive resistance to plant viruses: potential resistance genes beyond translation initiation factors. Front. Microbiol. 7:1695.

Kachroo, P., Yoshioka, K., Shah, J., Dooner, H. K., and Klessig, D. F. 2000 Resistance to turnip crinkle virus in Arabidopsis is regulated by two host genes and is salicylic acid dependent but NPR1, ethylene, and jasmonate independent. Plant Cell 12:677-690.

Komatsu, K., Hashimoto, M., Ozeki, J., Yamaji, Y., Maejima, K., Senshu, H., Himeno, M., Okano, Y., Kagiwada, S., and Namba, S. 2010. Viralinduced systemic necrosis in plants involves both programmed cell death and the inhibition of viral multiplication, which are regulated by independent pathways. Mol. Plant-Microbe Interact 23:283-293.

Kroner, P., and Ahlquist, P. 1992. RNA-based viruses. Pages 23-34 in: Molecular plant pathology; a practical approach. S. J. Gurr, M. J. McPherson, and D. J. Bowles, eds. Vol. 1. Oxford University Press, New York.

Lawton, K. A., Friedrich, L., Hunt, M., Weymann, K., Delaney, T., Kessmann, H., Staub, T., and Ryals, J. 1996. Benzothiadiazole induces disease resistance in Arabidopsis by activation of the systemic acquired resistance signal transduction pathway. Plant J. 10:71-82.

Lewsey, M. G., and Carr, J. P. 2009. Effects of DICER-like proteins 2, 3 and 4 on cucumber mosaic virus and tobacco mosaic virus infections in salicylic acid-treated plants. J. Gen. Virol. 90:3010-3014.

Liu, Y., Schiff, M., Marathe, R., and Dinesh-Kumar, S. P. 2002. Tobacco Rarl, EDS1 and NPR1/NIM1 like genes are required for N-mediated resistance to tobacco mosaic virus. Plant J. 30:415-429. 
Minato, N., Komatsu, K., Okano, Y., Maejima, K., Ozeki, J., Senshu, H., Takahashi, S., Yamaji, Y., and Namba, S. 2014. Efficient foreign gene expression in planta using a plantago asiatica mosaic virus-based vector achieved by the strong RNA-silencing suppressor activity of TGBp1. Arch. Virol. 159:885-896.

Murphy, A. M., and Carr, J. P. 2002. Salicylic acid has cell-specific effects on tobacco mosaic virus replication and cell-to-cell movement. Plant Physiol. 128:552-563.

Murphy, A. M., Gilliland, A., Eng Wong, C., West, J., Davinder, D. P., and Carr, J. P. 2001. Signal transduction in resistance to plant viruses. Eur. J. Plant Pathol. 107:121-128.

Nakashita, H., Yoshioka, K., Yasuda, M., Nitta, T., Arai, Y., Yoshida, S., and Yamaguchi, I. 2002. Probenazole induces systemic acquired resistance in tobacco through salicylic acid accumulation. Physiol. Mol. Plant Pathol. 61:197-203.

Noutoshi, Y., Okazaki, M., Kida, T., Nishina, Y., Morishita, Y., Ogawa, T., Suzuki, H., Shibata, D., Jikumaru, Y., Hanada, A., Kamiya, Y., and Shirasu, K. 2012. Novel plant immune-priming compounds identified via high-throughput chemical screening target salicylic acid glucosyltransferases in Arabidopsis. Plant Cell 24:3795-3804.

Otsuki, Y., Shimomura, T., and Takebe, I. 1972. Tobacco mosaic virus multiplication and expression of the $N$ gene in necrotic responding tobacco varieties. Virology 50:45-50.

Palukaitis, P., Yoon, J. Y., Choi, S. K., and Carr, J. P. 2017. Manipulation of induced resistance to viruses. Curr. Opin. Virol. 26:141-148.

Singh, D. P., Moore, C. A., Gilliland, A., and Carr, J. P. 2004. Activation of multiple antiviral defence mechanisms by salicylic acid. Mol. Plant Pathol. 5:57-63.

Takeshita, M., Koizumi, E., Noguchi, M., Sueda, K., Shimura, H., Ishikawa, N., Matsuura, H., Ohshima, K., Natsuaki, T., Kuwata, S., Furuya, N., Tsuchiya, K., and Masuta, C. 2012. Infection dynamics in viral spread and interference under the synergism between cucumber mosaic virus and turnip mosaic virus. Mol. Plant-Microbe Interact 25:18-27.

Takeshita, M., Okuda, M., Okuda, S., Hyodo, A., Hamano, K., Furuya, N., and Tsuchiya, K. 2013. Induction of antiviral responses by acibenzolar- s-methyl against cucurbit chlorotic yellows virus in Melon. Phytopathology 103:960-965.

Tanaka, M., Verbeek, M., Takehara, M., Pham, K., Lemmers, M., Slootweg, C., Arie, T., and Komatsu, K. 2019. Differences in infectivity and pathogenicity of two Plantago asiatica mosaic virus isolates in lilies. Eur. J. Plant Pathol. 153:813-823.

Tripathi, D., Jiang, Y. L., and Kumar, D. 2010. SABP2, a methyl salicylate esterase is required for the systemic acquired resistance induced by acibenzolar-S-methyl in plants. FEBS Lett. 584: 3458-3463.

Wang, D., Weaver, N. D., Kesarwani, M., and Dong, X. 2005. Induction of protein secretory pathway is required for systemic acquired resistance. Science 308:1036-1040.

Wei, H. L., Chakravarthy, S., Worley, J. N., and Collmer, A. 2013. Consequences of flagellin export through the type III secretion system of Pseudomonas syringae reveal a major difference in the innate immune systems of mammals and the model plant Nicotiana benthamiana. Cell. Microbiol. 15:601-618.

Wong, C. E., Carson, R. A., and Carr, J. P. 2002. Chemically induced virus resistance in Arabidopsis thaliana is independent of pathogenesis-related protein expression and the NPRl gene. Mol. Plant-Microbe Interact 15:75-81.

Xie, Z., Fan, B., Chen, C., and Chen, Z. 2001. An important role of an inducible RNA-dependent RNA polymerase in plant antiviral defense. Proc. Natl. Acad. Sci. U.S.A. 98:6516-6521.

Yamaji, Y., Maejima, K., Ozeki, J., Komatsu, K., Shiraishi, T., Okano, Y., Himeno, M., Sugawara, K., Neriya, Y., Minato, N., Miura, C., Hashimoto, M., and Namba, S. 2012. Lectin-mediated resistance impairs plant virus infection at the cellular level. Plant Cell 24:778-793.

Yan, S., and Dong, X. 2014. Perception of the plant immune signal salicylic acid. Curr. Opin. Plant Biol. 20:64-68.

Yoshida, T., Shiraishi, T., Hagiwara-Komoda, Y., Komatsu, K., Maejima, K., Okano, Y., Fujimoto, Y., Yusa, A., Yamaji, Y., and Namba, S. 2019. The plant noncanonical antiviral resistance protein JAX1 inhibits potexviral replication by targeting the viral RNA-dependent RNA polymerase. J. Virol. 93:e01506-18. 